\title{
Lire et écrire en Allemagne, aperçus sur l'histoire de son école rurale
}

\section{Rainer Riemenschneider}

\section{(2) OpenEdition \\ 12 Journals}

Édition électronique

URL : http://journals.openedition.org/trema/1901

DOI : 10.4000/trema.1901

ISSN : 2107-0997

Éditeur

Faculté d'Éducation de l'université de Montpellier

\section{Édition imprimée}

Date de publication : 1 décembre 1997

Pagination : 165-184

ISSN : 1167-315X

\section{Référence électronique}

Rainer Riemenschneider, «Lire et écrire en Allemagne, aperçus sur I'histoire de son école rurale »,

Tréma [En ligne], 12-13 | 1997, mis en ligne le 01 décembre 1997, consulté le 19 avril 2019. URL : http:// journals.openedition.org/trema/1901 ; DOI : 10.4000/trema.1901

Ce document a été généré automatiquement le 19 avril 2019

Trema 


\title{
Lire et écrire en Allemagne, aperçus sur l'histoire de son école rurale
}

\author{
Rainer Riemenschneider
}

1 Nous connaissons tous le vieil adage selon lequel le vainqueur de Sadowa et de Sedan, fut le maître d'école prussien. Des auteurs allemands et français, Ernest Renan en tête, ont dit et répété, dès 1866, que l'école primaire allemande avait non seulement jeté les bases de l'aptitude au maniement des armes, mais encore suscité l'élan national qui mena, grâce aux guerres successives, à l'unification de l'Allemagne. De part et d'autre du Rhin, on constatait la supériorité du système d'éducation allemand - constat qui, évidemment, ne mena pas aux mêmes conclusions chez le vainqueur et le vaincu. Mais ceci est une autre histoire: celle des rapports franco-allemands ou plutôt celle de l'antagonisme franco-allemand qui, heureusement, appartient désormais à l'histoire. S'il y a quelqu'un qui s'en félicite, c'est bien moi, car autrement, je ne serais pas parmi vous aujourd'hui.

2 Mon propos est modeste. Je veux vous parler de l'école rurale allemande, non pas en dressant un bilan exhaustif de l'état des recherches, mais en esquissant quelques axes de travail. A cette fin, j'ai mis à profit la synthèse récente du Handbuch der deutschen Bildungsgeschichte, une œuvre remarquable en six volumes dont quatre sont parus, qui offre un panorama vigoureux d'un secteur de la recherche qui est traditionnellement très pratiqué en Allemagne. La synthèse fait apparaître les points forts, mais aussi les lacunes de nos connaissances. Je signale cet ouvrage à celles et ceux d'entre vous qui voudraient s'informer sur l'histoire socio-culturelle allemande : œuvre incontournable, le Handbuch fera sans doute autorité pendant longtemps. J'ai mis également à contribution deux grandes synthèses d'histoire générale: la Deutsche Geschichte de Thomas Nipperdey, en trois volumes, couvrant toute la durée du 19e siècle, et la Deutsche Gesellschaftsgeschichte de Hans-Ulrich Wehler, qui couvre la période de 1700 à 1949 et dont 3 volumes sur 4 sont parus. De plus, j'ai consulté un certain nombre d'ouvrages spécialisés et des articles de fond sur des questions pointues que je n'énumérerai pas ici.

3 Après un premier point sur l'histoire de l'école élémentaire allemande, je parlerai en second lieu de l'école rurale et, enfin, j'évoquerai le cas concret d'une école rurale toute particulière, qui fut la mienne. Et puisque le goût de notre époque est au visuel, je 
tâcherai d'agrémenter ma démonstration par des illustrations. Quelques-unes de ces illustrations, pour banales qu'elles nous paraissent de par leurs motifs, n'en sont pas moins uniques pour l'auteur de ce travail puisqu'elles évoquent des souvenirs vécus.

\section{L'école primaire Allemande: dressage de sujets dociles ou foyer de modernisation?}

4 La prétendue supériorité du système d'éducation allemand, qui fut pendant très longtemps un auto-stéréotype extrêmement valorisant chez nous, a fini par être violemment contestée par une génération d'historiens critiques à partir des années 1960 . A la recherche des causes du nazisme et de l'avènement du régime nazi considéré, dans sa totalité, comme une catastrophe pour l'histoire allemande et universelle, ces historiens ont procédé à une révision radicale du passé allemand et des prémisses idéologiques qui ont servi à interpréter ce passé. Dans ce contexte, le courant contestataire a mis le doigt sur ce qu'il a identifié comme les tares du système d'enseignement. Développant ses problématiques à partir d'un concept normatif de la pédagogie émancipatrice (Kuhlemann 1993, p. 41), il plaçait le problème de la discipline au cœur du débat. On considérait l'école élémentaire, notamment l'école prussienne, comme un agent de l'Etat produisant des sujets dociles, soumis aux valeurs traditionnelles de la société, obéissant aux autorités établies, résignés au sort qui leur était réservé par la providence (Kuhlemann 1991, p. 179). L'Empire bismarckien et wilhelminien, donc l'époque de 1871 à 1918, était dans la ligne de mire de ces auteurs : l'éducation scolaire visait à la « Untertanenerziehung", spécialement l'enseignement de l'histoire imprégné d'un esprit autoritaire, antilibéral, antiparlementaire, militariste, voire raciste, au point qu'on a cru y voir les antécédents du nazisme (Kuhlemann 1991, p. 206).

5 Cette façon plutôt inédite de voir l'histoire allemande était salutaire à plus d'un titre : du point de vue politique, elle était tributaire d'une prise de conscience en Allemagne de l'Ouest mettant en relief les déficits de pensée et de pratique démocratiques dans la société ; cette prise de conscience induisait un changement en profondeur de culture politique, permettant à l'Allemagne de l'Ouest de rattraper en quelque sorte le niveau des autres démocraties occidentales. D'autre part, cette nouvelle façon de voir les choses était fructueuse du point de vue scientifique : la thèse de l'école comme instrument de l'Etat autoritaire a provoqué et stimulé la recherche. La multiplication de travaux destinés à nuancer cette thèse a permis d'étayer une autre approche du phénomène: celle de la modernisation. C'est le paradigme qui sert de fil conducteur au Handbuch der Bildungsgeschichte. L'auteur du chapitre sur les Écoles à l'époque de l'Empire de 1870 à 1918 (Kuhlemann 1993, p. 44), reprenant une formule de Dietrich Rüschemeyer, parle à ce propos de «modernisation partielle » pour mieux expliquer le changement structurel qui affecte le système éducatif.

Certains indices permettent de caractériser cette modernisation (Kuhlemann 1991, p. 92 sqq.).

7 1. Les dépenses accrues de l'État de Prusse pour l'école primaire : entre 1886 et 1911, ces dépenses augmentent de 29 Marks par élève à 65 Marks. Ces dépenses furent employées pour améliorer le salaire des instituteurs, mais surtout pour augmenter les postes d'enseignants. Ainsi, pour l'ensemble du pays, le nombre d'élèves par enseignant tombe de 75 en 1886 à 56 élèves en 1911. 
8 2. Autre aspect de la modernisation, la scolarisation obligatoire est devenue une réalité dès avant l'avènement de l'Empire, donc avant 1870, et plus tôt que dans la plupart des pays européens (François 1983).

Il faut voir là une conséquence de l'obligation scolaire (allgemeine Schulpflicht), proclamée de bonne heure dans plusieurs États allemands, surtout les États protestants :

- 1619: Weimarer Schulordnung

- 1642 : Gothaer Schulmethodus (l'enseignement primaire défini comme matière séculière et soustrait à l'ordre ecclésiastique)

- 1651 : l'Etat de Braunschweig, en instituant une inspection générale (Generalinspektorat), crée une institution étatique

- 1649: Wittenberg

- 1717 : Preuflen ; 1763 Generalschulreglement

- 1763 : Sachsen

- 1774 : Kurbayern, staatliche Schulordnung.

9 Cependant, il ne s'agissait encore que de déclarations d'intention. Vers 1800, environ $50 \%$ d'enfants seulement étaient scolarisés dans les différents États allemands, et pas toujours de façon régulière (Wehler I, pp. 285, 287) : beaucoup de jeunes quittaient l'école avant le terme de leur scolarité, ou s'absentaient temporairement, pour cause de travaux.

10 3. Liée à la scolarisation obligatoire, l'alphabétisation. Malgré d'importantes lacunes dans la recherche, on estime que les jeunes générations vivant sous l'Empire étaient pratiquement toutes alphabétisées. Une enquête de 1871 a montré que $87 \%$ de la population savaient lire et écrire - avec des variations régionales considérables. Ainsi, en Poméranie, le taux d'alphabétisation était de $60 \%$; en revanche, en Rhénanie et au Brandebourg, ce taux était respectivement de $91 \%$ et $97 \%$. Des sondages ultérieurs donnent à penser que la régression de l'analphabétisme fut un fait constant sous l'Empire.

11 Ainsi la modernisation était très largement due à l'impulsion de l'Etat qui, par des dépenses scolaires accrues et par la contrainte et un contrôle administratif de la scolarisation, veillait constamment à une augmentation du niveau culturel de la société.

12 Cependant, le pouvoir de l'Etat n'était pas illimité et se heurtait à des obstacles tenaces : des intérêts établis limitaient son action et empêchèrent longtemps le plein développement de la scolarité. Gros propriétaires, chefs d'entreprises, aristocratie foncière et clergé ne regardaient pas d'un bon œil la fréquentation de plus en plus longue de l'école par la jeunesse. Et très souvent ces intérêts obtenaient gain de cause. L'Etat composait avec eux, redoutant le conflit ouvert, d'où une modernisation partielle. Tous ces facteurs nuancent considérablement la thèse de l'Etat puissant, monarchiste et autoritaire (Kuhlemann 1991, p. 180). S'il y a un argument qui illustre ce fait, c'est bien le suivant : bien que l'Etat ait tout mis en œuvre pour contrecarrer l'expansion de la socialdémocratie, celle-ci est devenue, à l'issue des élections générales de 1912, la première force politique du Reich (Wehler III, p. 1197). Autant dire que bien d'autres facteurs, en dehors et à côté de l'école, ont façonné les esprits. 


\section{L'école rurale, parent pauvre de l'enseignement en Allemagne}

13 L'école prussienne avait été fondée par la monarchie absolue - et, après elle, par l'absolutisme éclairé - qui avait besoin de sujets loyaux et rompus au maniement des armes : pour comprendre les instructions militaires, il fallait être passé par l'école. Mais le véritable engouement social pour l'école date du $19^{\mathrm{e}}$ siècle. "La société allemande », écrit Thomas Nipperdey (I, p. 531), «était devenue, dans les deux premiers tiers du $19^{e}$ siècle, une société scolaire (Schulgesellschaft) ; le sort de l'individu dépendait de son parcours à l'école, c'est cela qui intéressait les familles». Or l'école rurale s'est taillé une belle part dans cet engouement, investissant durablement l'imaginaire social comme en témoignent de nombreuses représentations picturales.

$14 \mathrm{Au} 19^{\mathrm{e}}$ siècle, on rencontre fréquemment, en feuilletant des revues et des livres, des images mélancoliques du « bon vieux temps » qui suggèrent une image idyllique de l'école du village et expriment la nostalgie, face aux bouleversements de l'ère industrielle, d'une vie à la campagne saine, simple et vertueuse. Le mythe de l'école rurale apparaît ainsi comme le produit du désarroi des esprits et des changements brutaux du cadre et du mode de vie...

15 Mais la réalité scolaire avait d'autres visages. Le $19^{e}$ siècle a produit des tableaux montrant des écoles de villages aux salles exiguës, mal éclairées, surchargées d'élèves qui doivent partager le peu d'espace avec les animaux domestiques ou avec la famille du maître. Les tableaux d'Albert Anker (1831-1910), peintre de la Forêt Noire, sont un modèle du genre (on en trouve dans Schiffler/Winkeler, 1985 et 1991). Mais c'est la caricature qui exprime le plus crûment cette étrange cohabitation: forçant sans doute le trait; elle accuse les conditions de travail pesantes du maître d'école, qui frôle bien souvent la misère et se trouve contraint d'exercer un deuxième métier : sabotier, menuisier, et, presque toujours, agriculteur. 
Image 1 : Réalisée d'après un tableau, cette lithographie d'Adolf MENZEL (1815-1905), "Frédéric Guillaume $7^{\text {er }}$ visite une école " (1858) montre le roi-soldat (1713-1740), qui avait achevé l'absolutisme en Prusse, visitant une école de village.

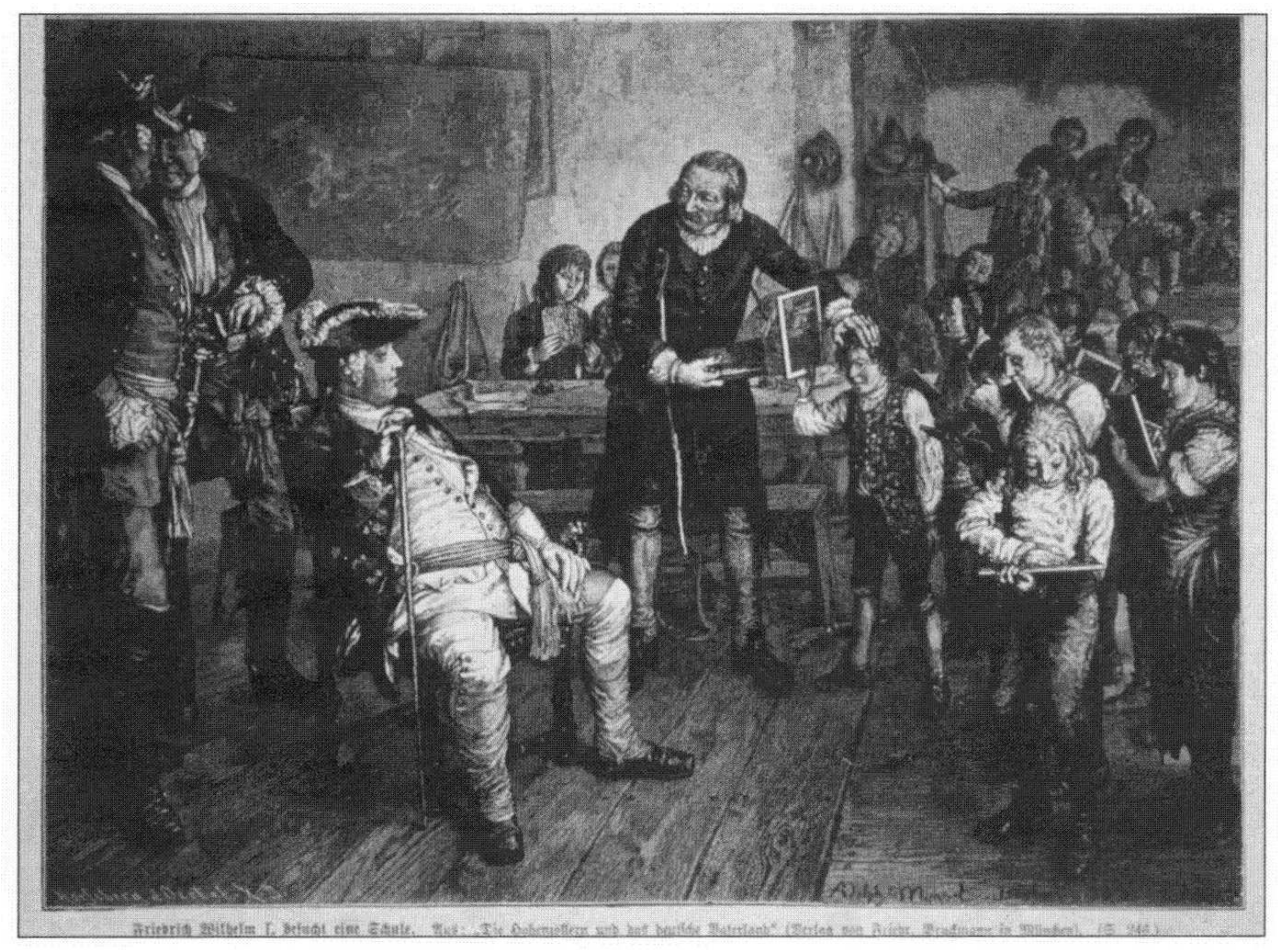

Crédits : Horst SCHIFFLER et Rolf WINKELER

Le métier d'instituteur est encore ingrat parce qu'il s'agit de faire régner la discipline dans une classe composée le plus souvent d'élèves de tous âges, filles et garçons, aux motivations les plus diverses. Dans les représentations, les filles sont toujours sages, bien rangées sur leurs bancs et appliquées. Elles contrastent avec les garçons qui, hors de la portée du maître, sont dissipés : ils causent en groupe, chahutent, voire disparaissent par la fenêtre à la faveur de la pénombre qui règne au fond de la salle. Aussi, le bâton, qui ne manque dans aucune image, est-il l'attribut obligé du maître d'école : il sert à montrer certes, mais aussi, et surtout, à punir. 
Image 2 : Le chemin de l'école rurale : un petit monde harmonieux et tranquille. Lithographie de Joseph NEPOMUK HEINEMANN (1825-1901).

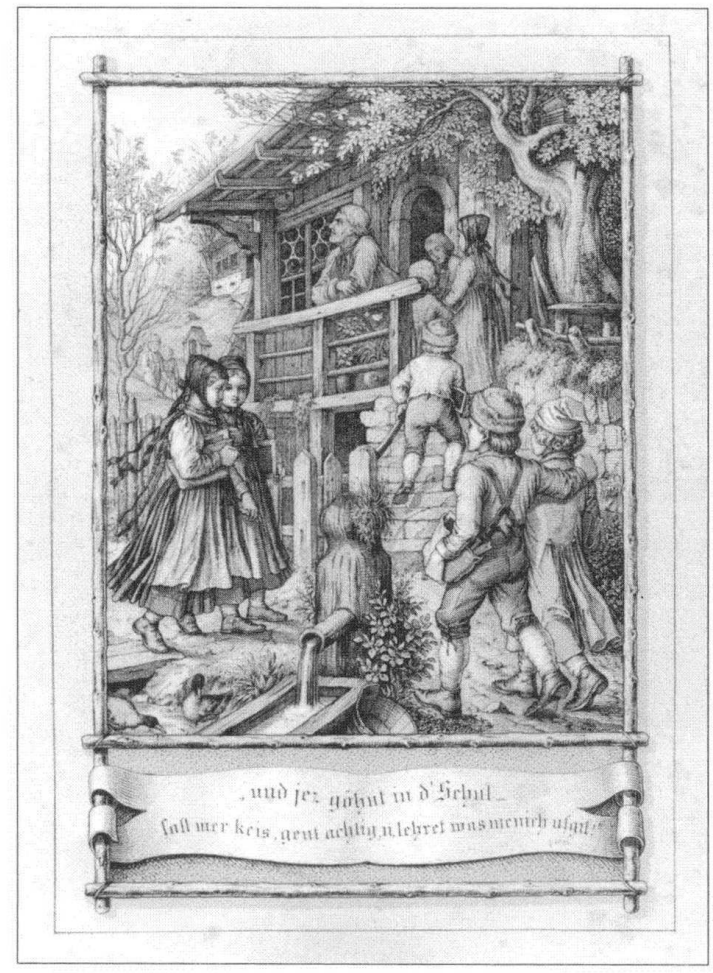

Crédits : Horst SCHIFFLER et Rolf WINKELER. 
Image 3 : "Schule im Spreewald " [Une école dans la forêt de la Spree]. Cette gravure sur bois, d'après un dessin de Joseph PUSCHKIN, nous transporte dans une région qui, loin des bruits des villes et des usines, a conservé un caractère quasi paradisiaque.

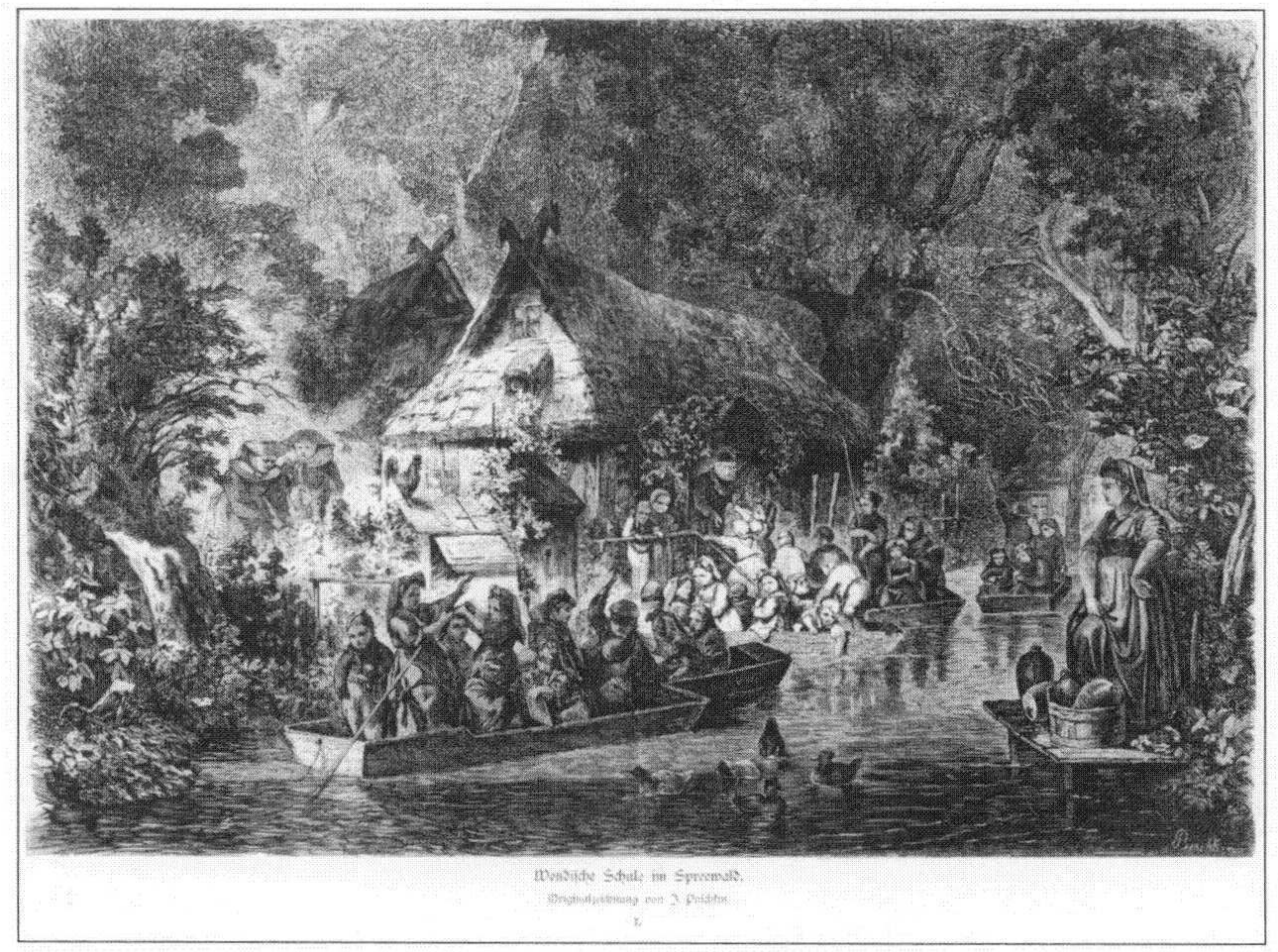

Crédits : Horst SCHIFFLER et Rolf WINKELER. 
Image $4: 1825$ : Les conditions matérielles de l'enseignement rural sont souvent lamentables. L'école antique, eau-forte coloriée de Johann NUSSBIEGEL (1750-1829).

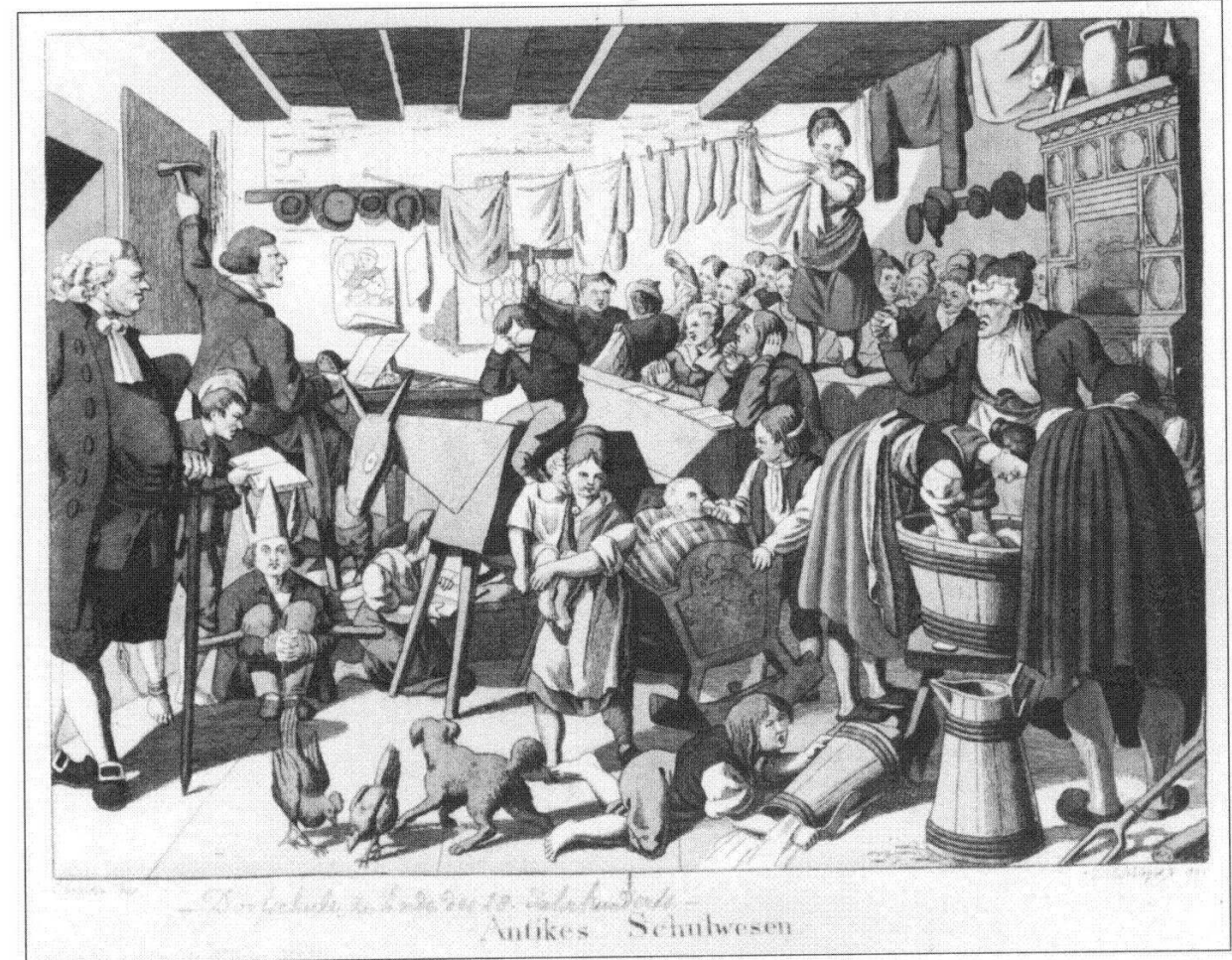

Crédits : Germanisches Nationalmuseum de Nürnberg 
Image 5 : L'instituteur en paysan (estampe, 1825) : Comment celui qui doit conduire les bœufs au labour pourrait-il se consacrer à son enseignement ?

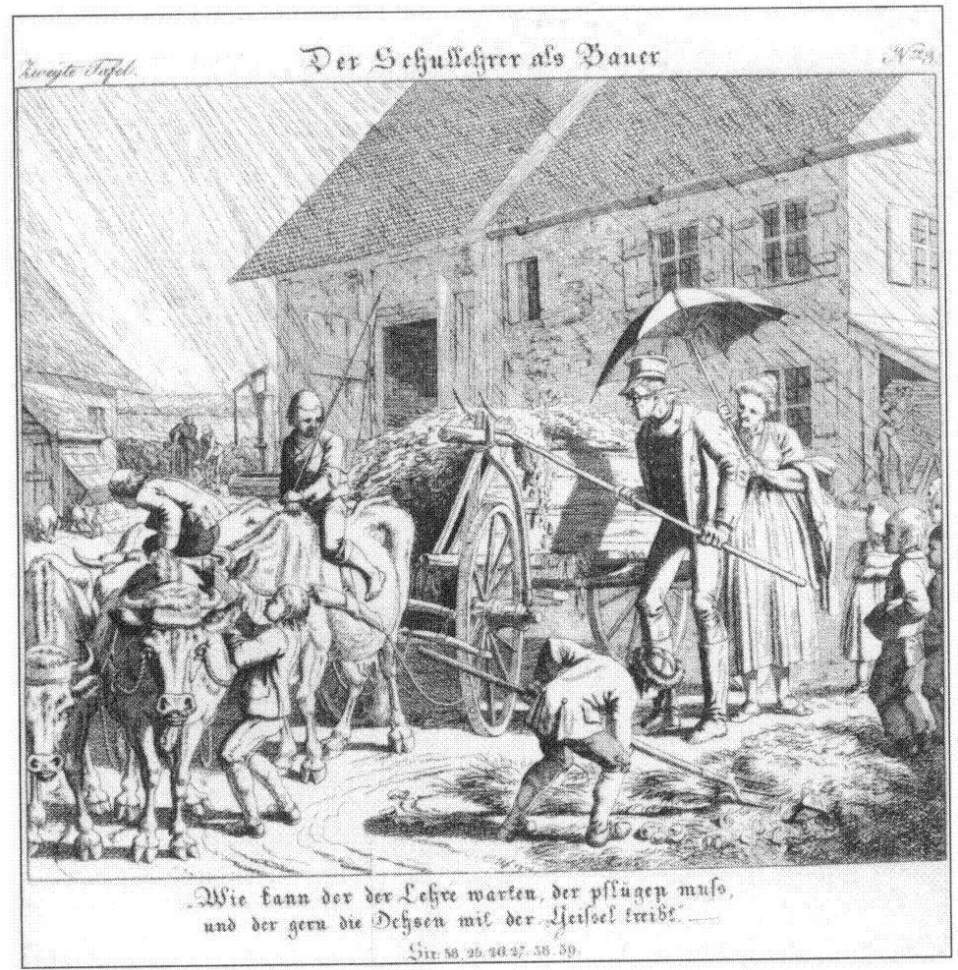

Crédits : Horst SCHIFFLER et Rolf WINKELER 
Image 6 : La punition comme procédé pédagogique. École de village Souabe, gravure sur bois coloriée d'après un tableau de Julius GEERTZ (1837-1902) : Le souffleur à l'école.

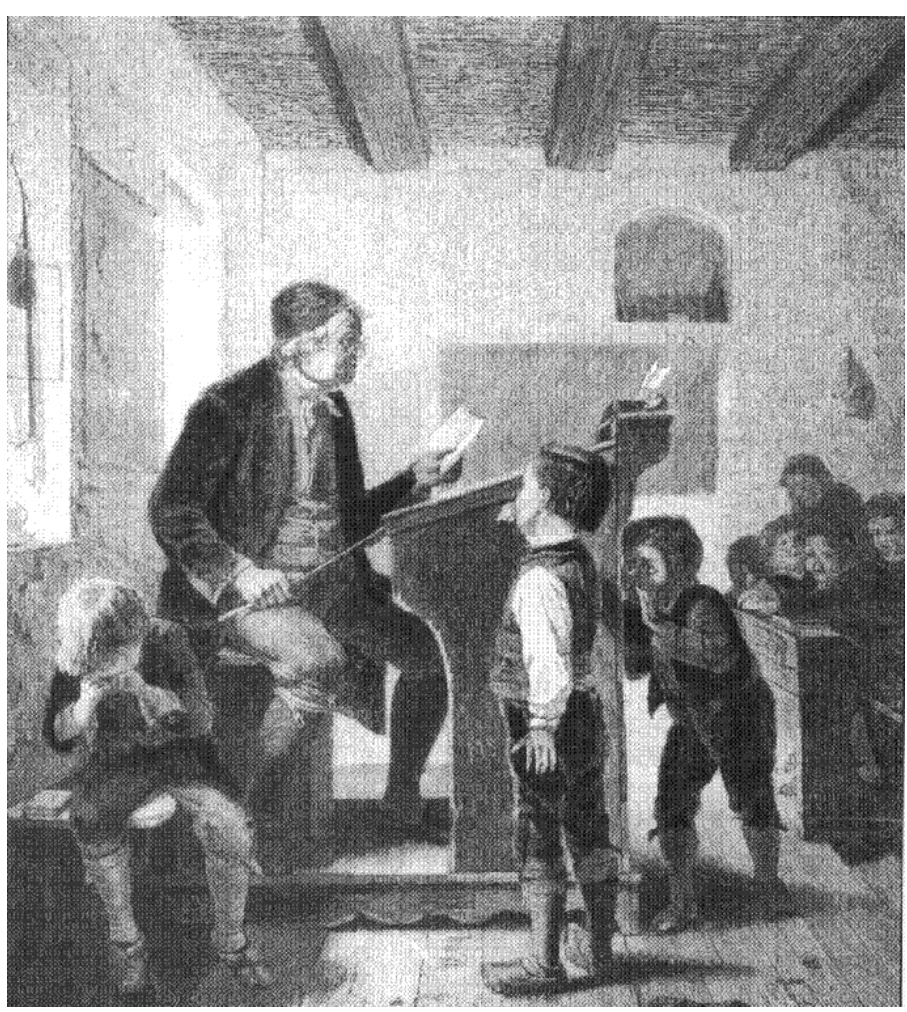

Crédits : Horst SCHIFFLER et Rolf WINKELER. 
Image 7 : Un maître d'école rurale en 1880 . Gravure sur bois d'après le tableau de Hugo KAUFMANN (1844-1915) « Der Herr Cantor »

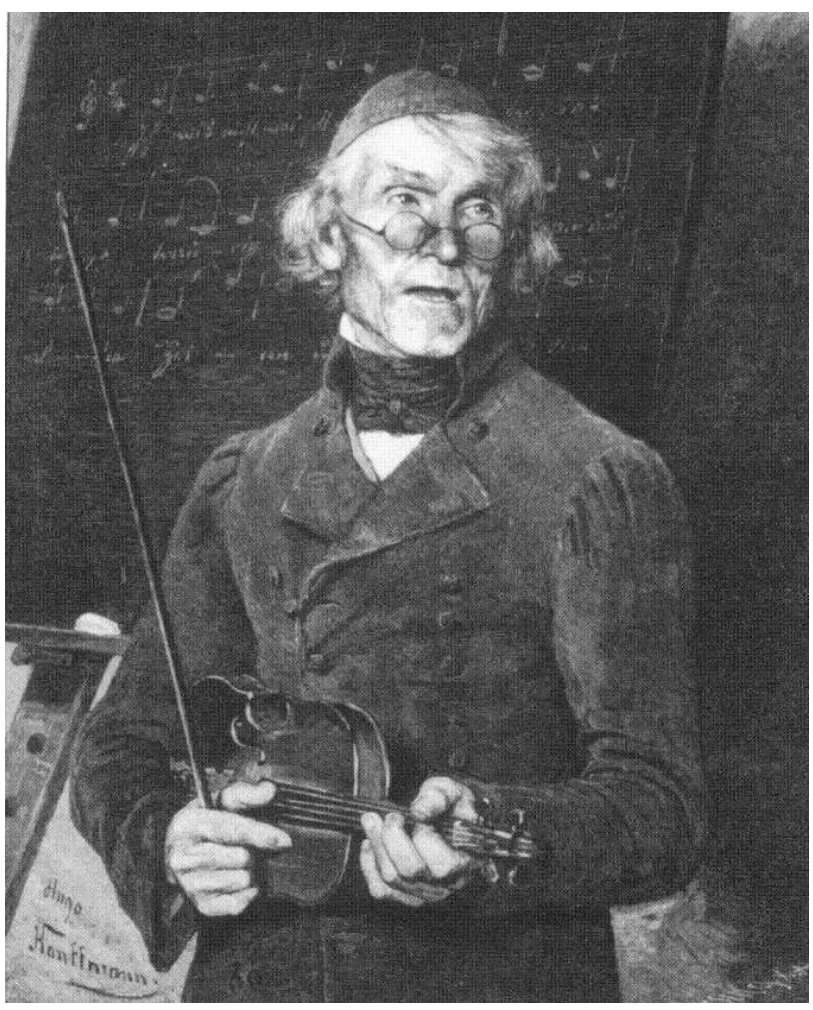

Crédits : Horst SCHIFFLER et Rolf WINKELER. comprenait pas ce qu'il devait enseigner - comment les pauvres élèves pouvaient-ils comprendre ce qu'ils devaient apprendre? Aussi la méthode de mémorisation était-elle souvent appliquée... à bâtons rompus. En 1779, un instituteur notait qu'au terme de 50 ans d'enseignement, il avait distribué «au bas mot » 911.527 coups de canne, 1.115.800 chiquenaudes, 136.715 gifles et 124.010 coups de verge (Rutenhiebe). (Mirow 1996, p. 407)! Le métier d'instituteur n'était sûrement pas une sinécure, puisque le maître d'école rural avait de multiples obligations : il devait tenir l'école, subvenir aux besoins de sa famille (le plus souvent nombreuse), satisfaire à une kyrielle de menues obligations, dont le service de bedeau, comme en témoigne la liste des tâches dressée pour le maître d'école d'Amelsen, près de Einbeck en 1795/96 (Schiffler/Winkeler 1985, p. 120, et note 35, p. 152).

Les illustrations révèlent souvent l'aspect misérable, besogneux, de cette condition et cette impression se vérifie quand on consulte les travaux de recherche qui font état d'un contraste brutal entre ville et campagne. L'école rurale fait figure de parent pauvre de l'enseignement primaire. Dans la hiérarchie des différents types d'écoles primaires, elle se trouve au plus bas, juste à proximité de l'école des pauvres (Armenschule)qui, dans les villes, accueillent les plus démunis (Wehler III, p. 399), les enfants des prolétaires qui ne peuvent payer la taxe scolaire pour leurs enfants ${ }^{1}$ (Wehler III., p. 1194).

L'école rurale allemande se signale en effet par un retard sensible par rapport à sa sœur de la ville, et cela dans la longue durée : tout au long des $18^{\mathrm{e}}, 19^{\mathrm{e}}$ et une partie du $20^{\mathrm{e}}$ siècle. Ce retard a été interprété par nombre de chercheurs comme un "déficit 
structurel » (Kuhlemann 1991, p. 193). Il était d'autant plus important, que l'école rurale a dominé très longtemps. Prenons l'exemple de la Prusse, tout en sachant que les autres États lui ressemblaient à cet égard. En 1886, la Prusse comptait 34.016 écoles primaires publiques. 89 \% de ces écoles étaient des écoles rurales. Un quart de siècle plus tard, en 1911, le chiffre a légèrement baissé : 86 \% d'écoles rurales qui, par le nombre, font preuve d'une grande stabilité. Mais les choses sont un peu différentes quand on considère le nombre des élèves. Entre 1886 et 1911, le nombre d'élèves diminue dans l'école rurale : de $68,9 \%$, il tombe à $61,2 \%$. Parallèlement, le nombre des élèves dans les écoles urbaines passe de $31,1 \%$ à $38,8 \%$. Donc, plus d'un tiers de la population scolaire fréquentait l'école de la ville au tournant du siècle, en Prusse. A contrario, les deux tiers des élèves fréquentaient l'école rurale qui pesait lourd dans la balance (Kuhlemann 1991, p. 193)!

Pour rendre compte du retard de modernisation de l'école rurale, la recherche fait état de quatre critères: le nombre de classes par école, le nombre d'élèves par classe et par enseignant, le financement des écoles, le contrôle exercé par le clergé (Kuhlemann 1991, pp. 194 et suiv.).

\subsection{Le nombre de classes par école}

Le poids des écoles à classe unique (Einklassigkeit) ou à mi-temps (roulement: matin/ après-midi) est considérable à la campagne. Par le terme « Einklassigkei », on entend que

"l'instituteur devait enseigner dans une seule salle de classe des enfants de 6 à Mans. Cela s'effectuait souvent par un partage en groupes. Pendant que l'enseignant s'occupait d'une partie des enfants, les autres travaillaient en silence à un autre devoir. Outre le fait que cette forme d'enseignement soumettait l'instituteur de village à d'énormes contraintes, il n'était guère possible à celui-ci d'aider au développement satisfaisant des capacités de chaque enfant en particulier, en raison des différences de maturité et de niveau des connaissances des élèves. De plus, ce partage en groupes entraînait une constante agitation, entravant un apprentissage efficient. On en vint, en partie précisément à cause de cette situation difficile à gérer par les enseignants, à créer des écoles fonctionnant à mi-temps. Mais si l'on réussit ainsi à réduire dans les classes les différences d'âge entre les enfants, ce fut au prix d'une diminution des heures de cours. » (Kuhlemann 1991, p. 194).

En 1886, 56,6\% des écoles rurales de Prusse étaient à classe unique, contre 15,2\% seulement dans les villes. En 1911, le rapport est de 39,2 \% contre 7,7 \% (Kuhlemann 1991, p. 217). Sur ce point, l'écart entre ville et campagne était écrasant.

\subsection{Le nombre d'élèves par classe et par enseignant}

Tandis que dans les villes, le nombre d'élèves par enseignant a considérablement baissé entre 1886 et 1911 (de 67 à 49), l'amélioration dans les campagnes n'a été que de 79 à 61 dans le même laps de temps. Mais ces chiffres moyens dissimulent des inégalités régionales. En effet, dans certaines régions, les conditions étaient dramatiques : dans la préfecture de Minden, par exemple, $29 \%$ des écoles rurales comptaient 80 à 120 élèves par enseignant et $70 \%$ de 120 à 200 élèves par instituteur ! (Kuhlemann 1991, p. 195).

\subsection{Le financement des écoles}

Le financement des écoles incombant essentiellement aux communes, le budget de l'école dépendait des dispositions de chaque commune en matière d'enseignement. Or si, dans 
les villes, l'esprit général était en faveur d'une amélioration de l'école, dans les campagnes les élites traditionnelles étaient surtout attachés à la bonne marche de l'économie, ce qui passait par une main d'oeuvre abondante. De ce point de vue, l'école était perçue comme un « empêcheur de danser en rond » et l'on ne voyait pas tellement la nécessité de voter beaucoup de crédits pour cette institution. Aussi l'école rurale demeurait-elle mal équipée et l'instituteur de village percevait un salaire nettement plus bas que son homologue des villes.

Tableau 1 :

Présentation du salaire moyen en Marks des Instituteurs et institutrices de Prusse. Tableau d'après Nipperdey (I, p. 543).

\begin{tabular}{|c|c|c|c|c|}
\hline \multirow[b]{2}{*}{ Année } & \multicolumn{3}{|c|}{ Salaires des Instituteurs } & \multirow{2}{*}{$\begin{array}{l}\text { Salaires des } \\
\text { Institutrices } \\
\text { Salaire moyen }\end{array}$} \\
\hline & Salaire moyen & Salaire en ville & Salaire à la campagne & \\
\hline 1878 & $1032 \mathrm{DM}$ & $1365 \mathrm{DM}$ & $874 \mathrm{DM}$ & - \\
\hline 1886 & $1292 \mathrm{DM}$ & $1635 \mathrm{DM}$ & $1133 \mathrm{DM}$ & $1108 \mathrm{DM}$ \\
\hline 1901 & $1901 \mathrm{DM}$ & $2381 \mathrm{DM}$ & $1640 \mathrm{DM}$ & $1472 \mathrm{DM}$ \\
\hline 1911 & 2178 DM & $3218 \mathrm{DM}$ & $2401 \mathrm{DM}$ & $1869 \mathrm{DM}$ \\
\hline
\end{tabular}

Même au début du $20^{\mathrm{e}}$ siècle, après des augmentations substantielles de salaire, une grande partie des instituteurs de village était toujours tributaire de sources de revenus complémentaires, telles que le service de bedeau etc. (Wehler III, p. 1199). Ces circonstances ne contribuaient pas à rendre l'état d'instituteur rural plus attrayant.

\subsection{Le contrôle exercé par le clergé}

26 A la différence de la France, l'Allemagne n'a pas connu le monopole étatique de l'enseignement. En Allemagne, comme dans de nombreux pays industrialisés - Etats-Unis, Grande-Bretagne, Belgique, Italie - le secteur public s'est créé en laissant simplement subsister les écoles d'obédience religieuse existant précédemment. Aussi, un autre obstacle à une modernisation réussie des écoles rurales résidait dans le fait que celles-ci restaient soumises à la surveillance du clergé. Et les prêtres exerçaient souvent une influence néfaste sur le programme d'enseignement et, au-delà, sur la condition de l'enseignant. Aussi une guérilla acharnée opposait souvent le prêtre et l'enseignant. Bien que l'instituteur, en tant que pédagogue, fût en général plus compétent que le prêtre en matière d'enseignement, ce dernier, fort de sa position privilégiée auprès des villageois, faisait souvent sentir son mépris au maître d'école. De nombreux prêtres n'effectuaient les tours d'inspection des écoles que très sommairement ; ils négligeaient les conférences pédagogiques destinées à assurer la formation continue des maîtres, que l'Etat leur avait donné charge de diriger, et distribuaient dans certaines régions de très nombreuses dispenses de classe aux élèves à l'époque des moissons. Dans bien des villages, la dernière année de classe était notamment sacrifiée: au lieu d'achever normalement les huit années de classe obligatoires, les enfants étaient prématurément mis à contribution pour les travaux agricoles, et ce phénomène peut s'observer jusqu'au $20^{\mathrm{e}}$ siècle.

En fin de compte, la modernisation des écoles rurales en Prusse était donc placée sous de mauvais auspices. La question mal réglée du financement et de la surveillance des écoles, ainsi que l'absence d'un "système scolaire " similaire à celui qui se mettait en place dans les villes, creusèrent le fossé séparant écoles rurales et écoles des villes. Le député Albert 
Ernst mit très justement le doigt sur cet état de fait quand il déclara en 1906, dans l'enceinte du Parlement prussien: «Les écoles rurales sont généralement les laissées pour compte de l'Etat ». (Kuhlemann 1991, p. 196).

Tous ces facteurs autorisent la recherche à parler de «conditions catastrophiques de l'école rurale » (Kuhlemann 1991, p. 195) ou de « scandale public »(Wehler III, p. 1195).

Le contraste ville/campagne a persisté longtemps, jusqu'au début du $20^{\mathrm{e}}$ siècle. Ainsi le nombre de classes par école ne change guère après 1918. A cette date, si l'on considère l'ensemble du territoire allemand, dans les villages - plus précisément dans les communes de moins de 2000 habitants - $73 \%$ des écoles ne comptent qu'une ou deux classes (Zymek 1989, p. 167). C'est alors qu'on finit par qualifier l'école rurale à classe unique ou à deux classes par le terme péjoratif de "Zwergschule ", que l'on peut traduire par " école naine " ou « école de nains », les deux acceptions sont pertinentes puisque, aux dires de certains, l'école naine produit nécessairement des nains du point de vue de l'intellect.

Cependant, l'école rurale naine conserve ses fervents défenseurs, dans la lignée des conservateurs des "Stiehlsche Regulative» de 1854, jusqu'aux années 1960 de ce siècle, moment où l'on décide de sa disparition. Le deuxième président de la République Fédérale, Heinrich Lübke, fut un représentant notoire de cette tendance dans les années 1960.

\section{Melverode, ou le destin d'une école rurale allemande}

31 L'auteur de cette contribution est un produit vivant d'une école rurale qui venait de sortir tout juste de l'état d'école naine au moment où il y entra, en 1949, année de naissance des deux États allemands. C'est en évoquant le sort d'une école rurale par le biais d'une expérience personnelle que je veux compléter cet exposé en apportant un peu de couleurs aux traits nécessairement pâles des chiffres et explications théoriques. Je vous propose donc de parler de mon école, celle où j'ai appris à lire et à écrire et qui, par bien des traits, est assez représentative de l'évolution de l'école rurale en Allemagne en général.

Cette école est située dans l'ancien village de Melverode qui, avec ses fermes, ses champs et ses prairies, se trouvait jusqu'aux années 1950 de ce siècle aux portes de la ville de Braunschweig, dans le land de Basse-Saxe. Phagocyté depuis par la ville tentaculaire, ce village se trouve aujourd'hui noyé dans la banlieue de cette même ville. Domicile des " rur-bains », il est devenu un quartier-dortoir à force d'avoir toujours un peu sommeillé au cours de sa longue histoire. En effet, le village de Melverode, dont les origines remontent au haut Moyen-Age, n'a jamais connu le statut de municipalité : d'abord, parce qu'il était trop petit, et ensuite, parce qu'il était trop près de la grande ville. Pour la même raison, ce village, dont l'église romane est pourtant remarquable, n'a jamais eu de curé ou de pasteur pour lui tout seul. L'office religieux a toujours été assuré par le pasteur du village voisin. Mais Melverode a toujours eu son école. Et même, cette localité peut se targuer de conserver trois bâtiments d'école, d'époques différentes, qui symbolisent les étapes successives de l'histoire de l'école rurale allemande. 


\section{Les avatars de l'école de Melverode} grandes salles de classe aux plafonds démesurément hauts, où vivent deux instituteurs. Agrandie après 1945 par une troisième salle - en raison de l'afflux de réfugiés venus des territoires perdus à l'Est ou de la zone d'occupation soviétique - l'école est fermée en 1964 puis transformée, à son tour, en café.

\section{Images 8.}

La première école de Melverode, désaffectée en 1910 (photo du bas). Plusieurs décennies plus tard l'école est devenue un café (photo du haut).

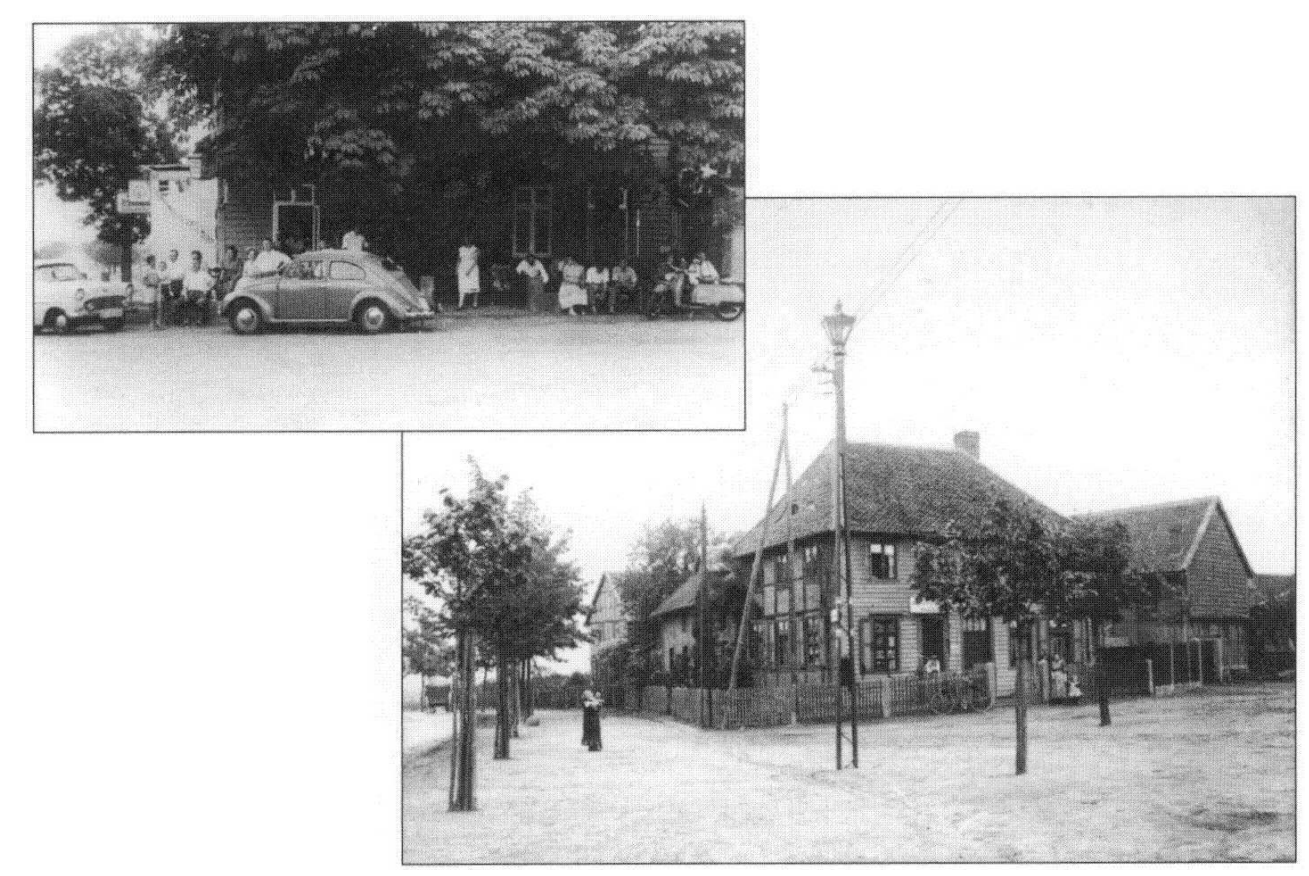

Photo de Christa Weiss

Enfin, en 1964, une troisième école s'ouvre à Melverode, au centre des nouveaux quartiers d'habitation. C'est une très grande école, avec de nombreux équipements dont un terrain de sport. Quel sort lui sera-t-il réservé ? Finira-t-elle en bistrot, comme les précédentes, ou peut-être en discothèque ? Faut-il pleurer, faut-il rire d'une telle éventualité ? Autant de questions qui restent sans réponse.

En tout cas, si la fermeture de l'école ancienne en 1910 et l'ouverture d'une nouvelle école symbolisaient l'expansion socio-économique due à l'industrialisation de la grande ville toute proche de Braunschweig, l'inauguration de l'école actuelle en 1964 est l'expression de l'urbanisation de Melverode même, conséquence du «miracle» économique aux lendemains de la seconde Guerre mondiale.

Cette évolution s'est traduite par un accroissement régulier de la population scolaire. Vers 1890, l'école compte une trentaine d'élèves avec un seul instituteur (Cf., image 11). En 1935, on compte 80 élèves et deux instituteurs ( $C f$., image 12). Après 1945, plus de 150 
élèves fréquentent l'école, encadrés par trois instituteurs et une auxiliaire pour les travaux « pratiques » : la couture et la cuisine.

Cependant le bombardement de Braunschweig par la Royal Air Force, le 22 octobre 1944, frappe le village de Melverode. Si, comme par miracle, l'église du village, au milieu des bâtiments endommagés, est restée indemne, plusieurs granges deviennent la proie des flammes et l'école est à moitié détruite. A cet égard, le cas de Melverode n'est pas représentatif des écoles rurales qui, en général, n'ont pas été touchées, les villages éloignés des villes et des complexes industriels ayant été épargnés par les bombardements. C'est précisément ici que la proximité de la grande ville industrielle a joué un rôle néfaste : les bombardiers, en attaquant Braunschweig, ont lâché une partie de leur cargaison de bombes trop tôt.

Il fallait donc reconstruire et remettre l'école en état de service. En juin 1949, le bâtiment, réparé, accueillit les élèves dans trois salles de classe. Le 29 juin eut lieu l'inauguration officielle, avec discours des autorités et concours sportif de la jeunesse scolaire.

Mais ce n'était pas la fête tous les jours. On le mesure en consultant la correspondance entre l'administration des écoles à Braunschweig et le nouveau directeur de l'école de Melverode, mon père, Hans Riemenschneider nommé en 1946. Prise aux environs de 1950 devant le mur rugueux de l'école restaurée, une photo ( $C f$., image 14) montre un homme qui n'a pas atteint 50 ans mais qui paraît beaucoup plus que son âge: il avait été continuellement sous les armes, de 1940 à 1945, en France, puis en Russie, et la dure épreuve du front s'est gravée dans ses traits. Revenu de la guerre, il devait, dans un monde en ruines, nourrir une famille de cinq enfants avec un salaire dont on a vu qu'il n'était pas brillant. D'où la nécessité d'une autre source de revenus : l'agriculture devint son second métier.

41 Ce qui ressort de la correspondance entre le directeur de l'école de Melverode et l'administration des écoles à Braunschweig, c'est le manque d'argent qui revient comme un leitmotiv : l'administration, parcimonieuse, réduit les demandes de dépenses même les plus urgentes en évoquant l'état désastreux des finances de la ville.

42 Ainsi, quand il fallut remplacer le mobilier scolaire détruit dans le bombardement, l'administration réduisit le devis de $630 \mathrm{DM}$ à $490 \mathrm{DM}$ (Lettre du directeur d'école à l'Office des écoles du 20 janvier 1949).

43 Ainsi, la subvention de $400 \mathrm{DM}$ demandée par l'école à la ville pour régaler les élèves lors de la fête d'inauguration de l'école le 29 juin 1949 (Lettre du même au Président du comité des écoles, le Prof. Staats, du 15 juin 1949) est réduite à $100 \mathrm{DM}$, « eu égard à la situation financière particulièrement défavorable de la ville » (Lettre-réponse du Prof. Staats, 25 juin 1949).

44 Ainsi la nécessaire modernisation des installations sanitaires - des toilettes collectives demandée, pour des raisons d'hygiène, par le directeur en termes insistants et avec force détails (Lettre du directeur du 26 mai 1949) est refusée par l'administration : estimée à 5000 DM, la dépense est jugée trop élevée. Voici les raisons invoquées :

"Il faut bien reconnaître en effet que les toilettes ne répondent pas aux critères des installations modernes. Cependant, la difficile situation financière actuelle me contraint à faire la juste remarque que ces installations sanitaires existent depuis plus de 40 ans et que leur état actuel ne s'est nullement modifié ou détérioré par rapport à l'état initial. Si, le nombre des élèves augmentant, une utilisation plus fréquente des toilettes venait à poser des problèmes, on pourrait y remédier en vidangeant plus souvent les fosses. Nous nous efforçons dans la mesure du possible d'apporter des améliorations aux installations 
sanitaires des écoles, mais malgré tout, nous ne sommes tenus de n'intervenir que dans les cas vraiment graves, dont l'école de Melverode ne fait sans aucun doute pas partie. Je suis donc au regret de ne pouvoir répondre présentement à votre demande de modernisation des toilettes de l'école de Melverode, me permettant de rappeler à nouveau que la situation financière actuelle n'autorise malheureusement une intervention au niveau des bâtiments publics que dans les situations les plus urgentes. " (Lettre de l'architecte en chef, Oberbaurat Dr. Böhlke, au Prof. Staats du 14 juin 1949). de la guerre totale, l'école allemande - dont l'école rurale - a produit des résultats remarquables dans la mesure où elle a formé des générations d'Allemands et d'Allemandes capables des plus grands efforts, pour le meilleur et pour le pire. Ce sont ces vertus jugées spécifiquement européennes - la discipline, le sens de l'ordre, la satisfaction des pulsions différée, l'économie, la capacité d'innovation - qui ont rendu possible la production industrielle de masse et donc le "miracle allemand». En revanche, c'est l'habitude prise de la consommation de produits de masse qui, à son tour, dissout ces 
mêmes vertus dans nos sociétés industrielles (von Borries, 1997, p. 89). La fin de l'école rurale symboliserait-elle le ressort brisé de l'accumulation des richesses des sociétés modernes?

Image 9. : 1910 : la « nouvelle école » de Melverode.

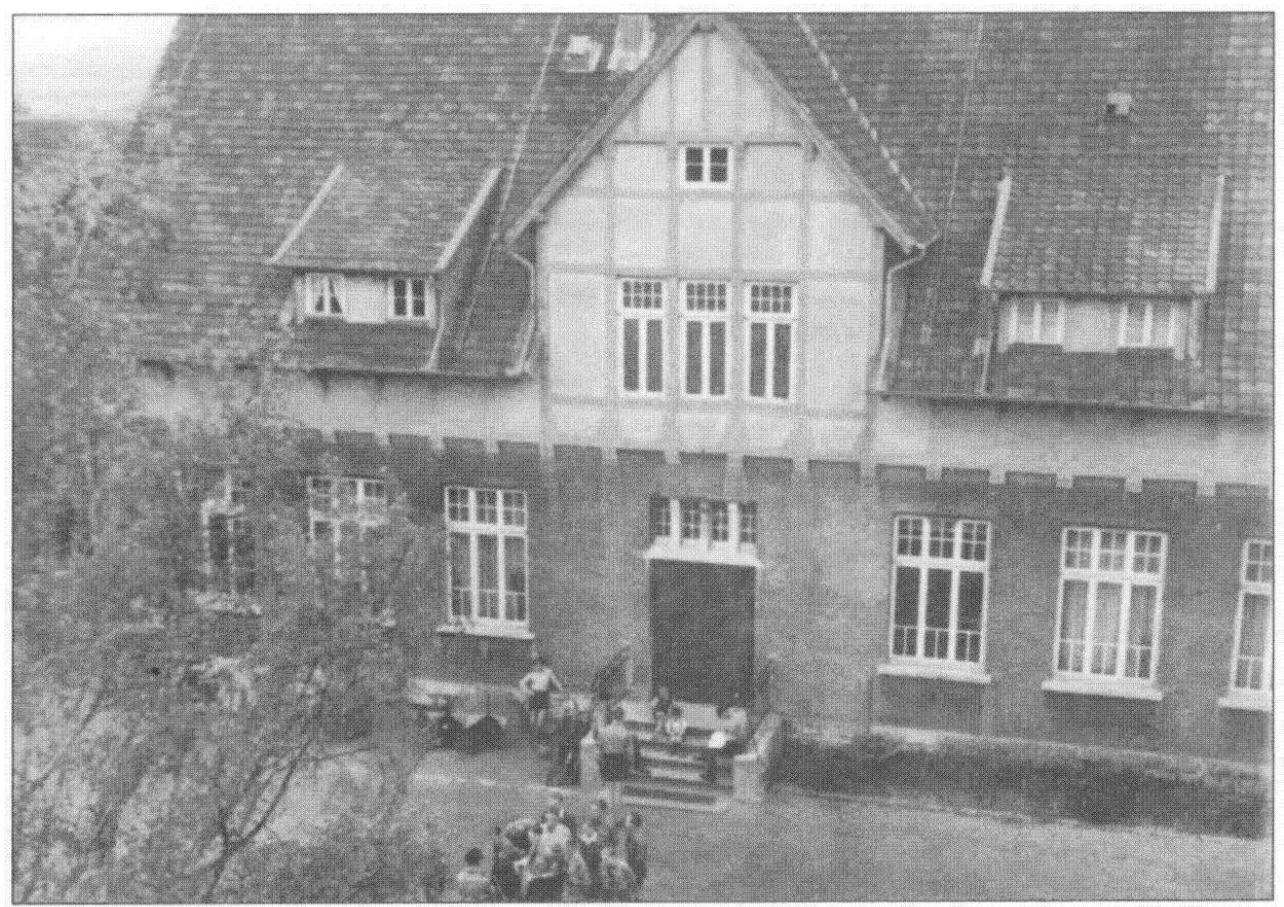

Photo de Christa WEISS

Image 10. : Une aile de l'école actuelle de Melverode inaugurée en 1964.

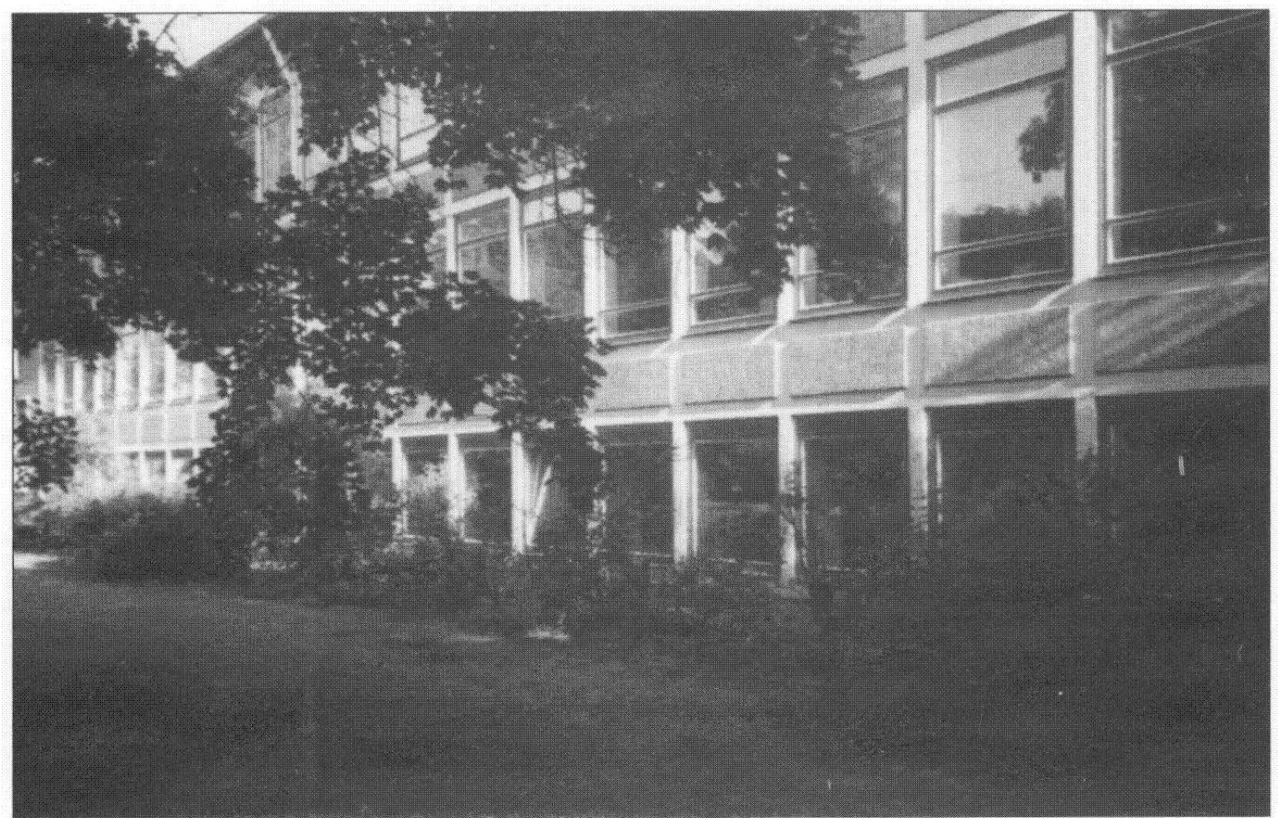

Photo de Rainer RIEMENSCHNEIDER 
Image 11 : Vers $1890: 33$ élèves, un instituteur.

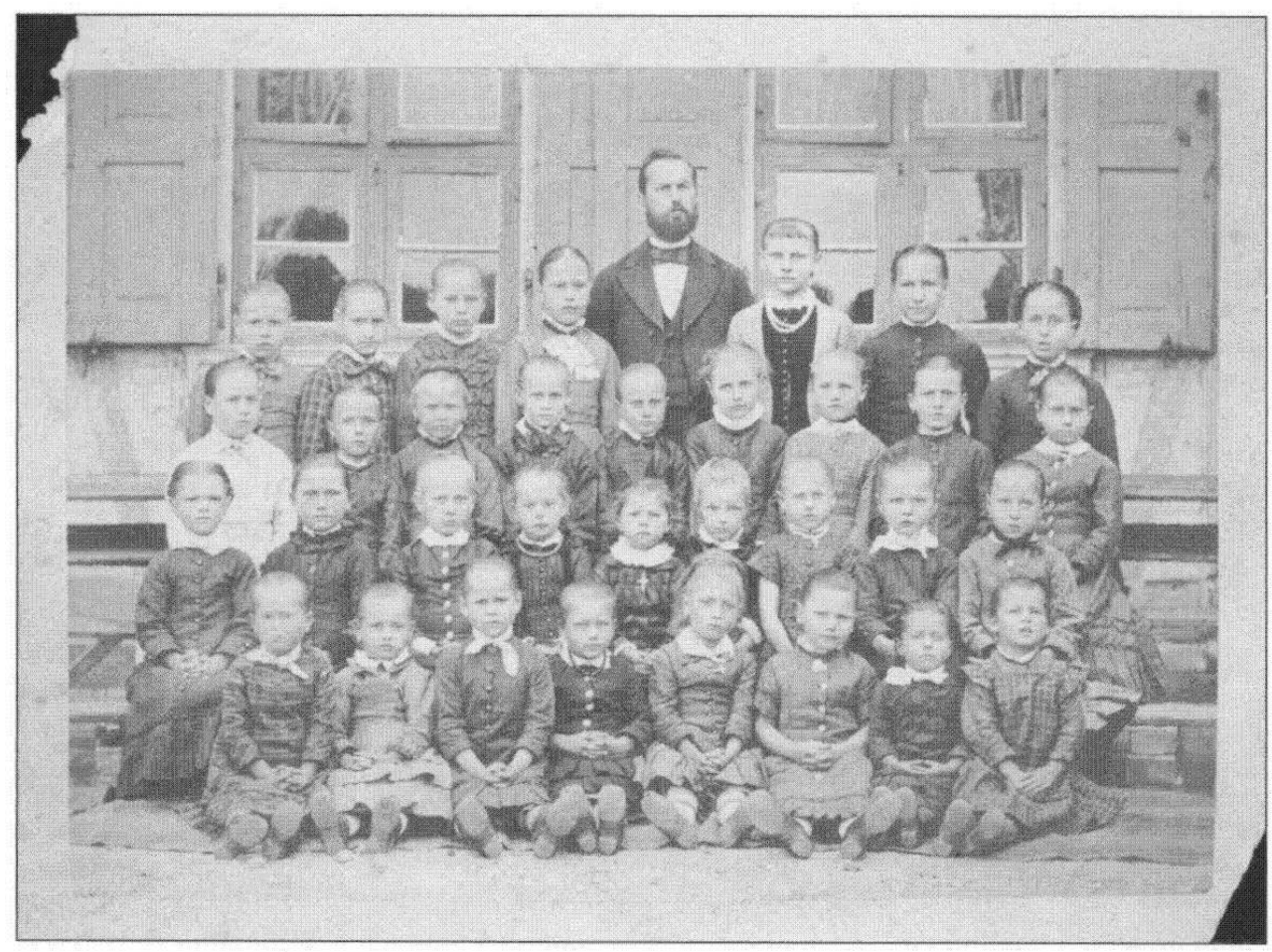

Photo de Christa WEISS

Image 12 : En 1935 : 78 élèves, deux instituteurs.

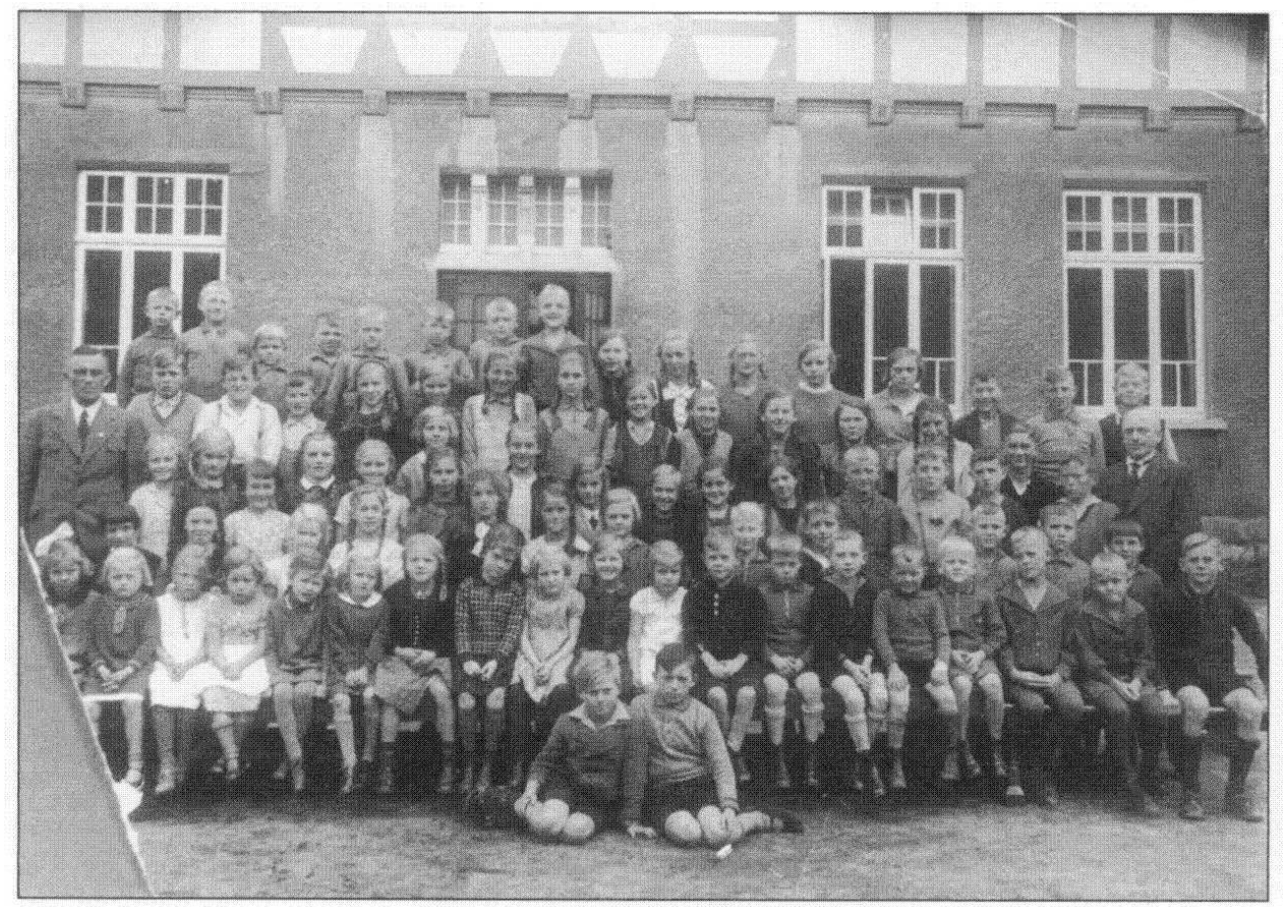

Photo de Christa WEISS 
Image 13 : 1944 : l'école en ruines après un bombardement, photo prise du clocher de l'église. Elle sera reconstruite en 1948-1949.

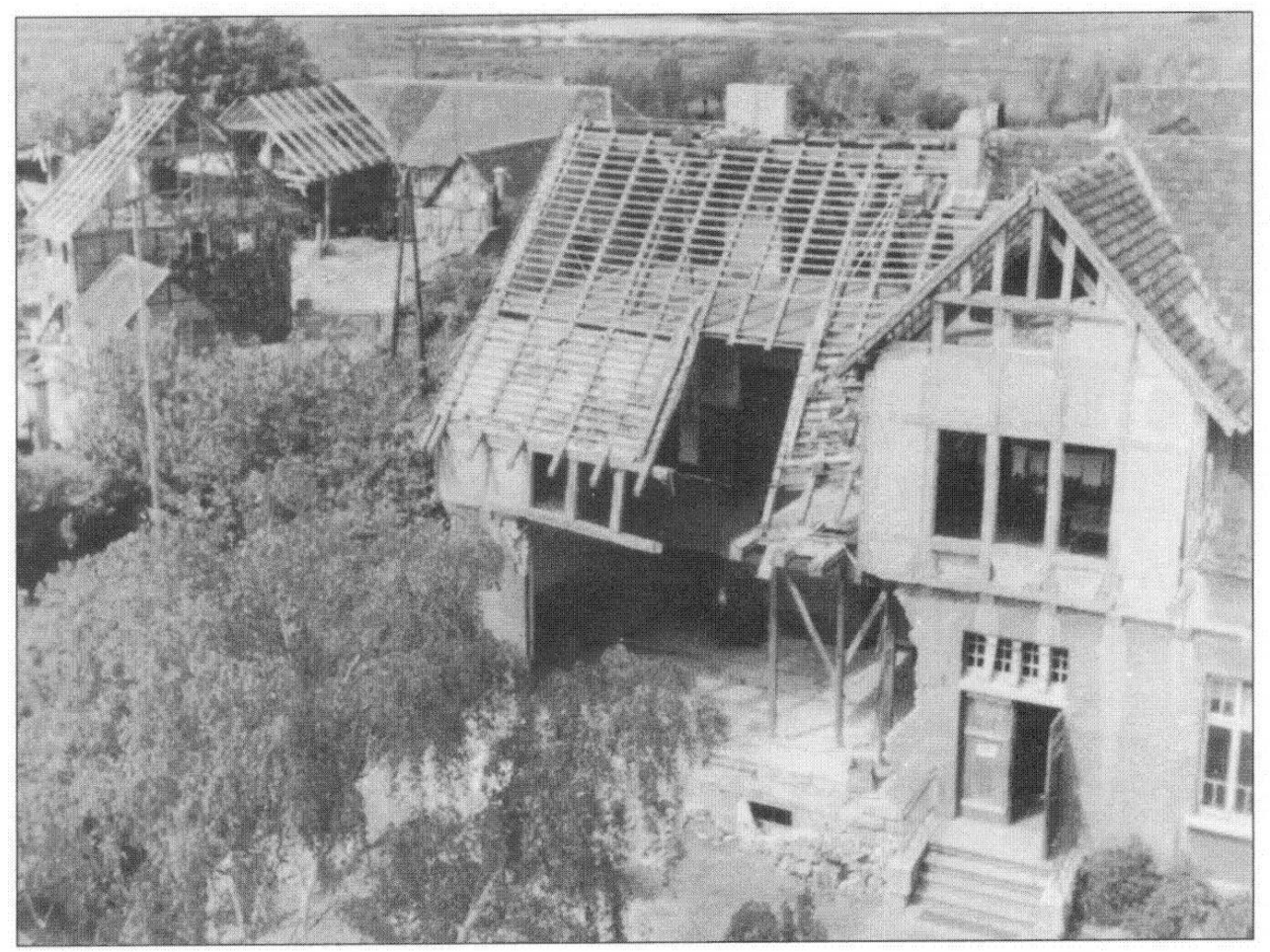

Photo de Christa WEISS 
Image 14 : Hans RIEMENSCHNEIDER (2 avril 1904 - 24 décembre 1960), directeur de l'école de Melverode.

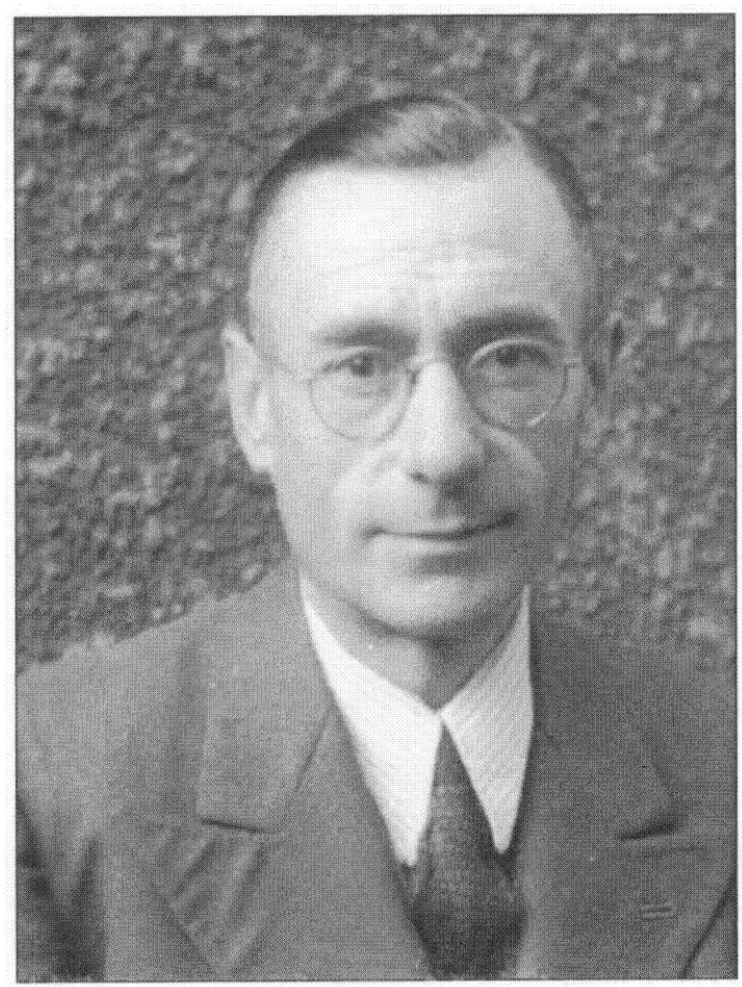

Photo de Christa WEISS

\section{BIBLIOGRAPHIE}

BLOCK R., Der Alphabetisierungsverlauf im Preuáen des 19. Jahrhunderts : quantitative Explorationen aus bildungshistorischer Perspektive, Frankfurt am Main [u.a.] 1995.

BÖLLING R., « Elementarschullehrer zwischen Disziplinierung und Emanzipation : Aspekte eines internationalen Vergleichs (1870-1940) », in Bildung. Staat, Gesellschaft im 19. Jahrhundert : Mobilisierung u. Disziplinierung / hrsg. von Karl-Ernst Jeismann, Stuttgart, Steiner, 1989, S. 326-342. BORRIES B. von., « Dritte Welt und Geschichtslernen », in Handbuch der Geschichtsdidaktik, $5^{\mathrm{e}}$ édition refondue, Seelze 1997, pp. 87-91.

FRANÇOIS E., « Alphabetisierung in Frankreich und Deutschland während des 19. Jahrhunderts », inZeitschrift für Pädagogik 29,1983, pp. 755-768.

HANDBUCH DER DeUTSCHEN BILDUNGSGESCHICHTE /hrsg. von Christa Berg., München : Bd. 1. 15. bis 17. Jahrhundert : von der Renaissance und der Reformation bis zum Ende der Glaubenskämpfe / hrsg. von Notker Hammerstein, Unter Mitwirkung von August Buck, 1996. 475 S. Bd. 3. 1800-1870 : von der Neuordnung Deutschlands bis zur Gründung d. Dt. Reiches / hrsg. von Karl-Ernst Jeismann u. Peter Lundgreen, 1987, 442 S. Bd. 4. 1810-1918 : von der Reichsgründung bis zum Ende des Ersten 
Weltkriegs / hrsg. von Christa Berg. 1991. 582 S. (cit. : Kuhlemann 1991). Bd. 5. 1918-1945 : die Weimarer Republik und die nationalsozialistische Diktatur / hrsg. von Dieter Langewiesche und Heinz-Elmar Tenorth. - 1989, 470 S. (cit. : Zymek. 1989).

KUHLEMANN F.-M., « Tradition und Innovation. Zum Wandel des niederen Bildungssektors in Preussen 1790-1918 ", in Jahrbuch für Historische Bildungsforschung,hrsg. Historische Kommission der DGfE, Band 1, Weinheim/München 1993, p. 41-67, cit. : Kuhlemann, 1993.

LUNDGREEN P., SOZIALGESCHICHTE DER DEUTSCHEN SCHULE IM ÜBERBLICK, Göttingen : T. 1 : 1770-1918(1980). T. 2 : 1918-1980 (1981).

LUNDGREEN P., «Deutsche Bildungsgeschichte des 19. Jahrhunderts im internationalen Vergleich ", in Bildungsgeschichte und historisches Lernen :Symposium aus Anlass d. 65. Geburtstages von Prof. Dr. Karl-Ernst Jeismann. Braunschweig, 19-21 September 1990 / hrsg. von Ernst Hinrichs u. Wolfgang Jacobmeyer, Frankfurt/Main 1991. (Studien zur internationalen Schulbuchforschung, 67, S. 65-75).

MIROW J., Geschichte des deutschen Volkes. Von den Anfängen bis zur Gegenwart,édition revue et augmentée, Köln 1996.

NIPPERDEY T., Deutsche Geschichte : 1866-1918, München, Beck. Bd. 1 : Arbeitswelt und Bürgergeist, 1990. Bd. 2 : Machtstaat vor der Demokratie. - 2., durchges. Aufl., 1993, 948 S.

SCHIFFLER H. \& WINKELER R., Bilderwelten der Erziehung : die Schule im Bild des 19. Jahrhunderts, Weinheim [u.a.] 1991.

SCHIFFLER H. \& WINKELER R., Tausend Jahre Schule : eine Kulturgeschichte des Lernens in Bildern, Stuttgart [u.a.] 1985.

WEHLER H.-U., Deutsche Gesellschaftsgeschichte, München : Bd. 1 : Vom Feudalismus des Alten Reiches bis zur defensiven Modernisierung d. Reformära 1700-1815, 1987. Bd. 2 : Von der Reformära bis zur industriellen und politischen "Deutschen Doppelrevolution" 1815-1845/49, 1987. Bd. 3 : Von der “Deutschen Doppelrevolution” bis zum Beginn des Ersten Weltkrieges 1849-1914, 1995.

\section{NOTES}

1. Cette taxe sera abolie en 1880 .

\section{INDEX}

Mots-clés : Allemagne, école primaire, ruralité

Keywords : Germany, primary school, rural context, rural life

\section{AUTEUR}

\section{RAINER RIEMENSCHNEIDER}

Georg-Eckert-Institut, Braunschweig 